\title{
Future access to essential services in a growing smart city: The case of Surrey, British Columbia
}

\author{
Jerome R. Mayaud ${ }^{1 *}$, Martino Tran $^{1 *}$, Rafael H. M. Pereira ${ }^{2,3}$, Rohan Nuttall ${ }^{4}$ \\ ${ }^{1}$ School of Community and Regional Planning, Faculty of Applied Science, University of British \\ Columbia, 6333 Memorial Road, Vancouver, V6T 1Z2, Canada \\ ${ }^{2}$ Institute for Applied Economic Research (Ipea), Brasilia, Brazil \\ ${ }^{3}$ Transport Studies Unit (TSU), School of Geography and the Environment, University of \\ Oxford, South Parks Road, Oxford, UK \\ ${ }^{4}$ Department of Physics and Astronomy, 6224 Agricultural Road, Vancouver, V6T 1Z1, \\ Canada
}

${ }^{*}$ Corresponding author. E-mail address: jerome.mayaud@gmail.com; martino.tran@ubc.ca

\section{Abstract}

The concept of accessibility - the ease with which people can reach places or opportunities lies at the heart of what makes cities livable, workable and sustainable. As urban populations shift over time, predicting the changes to accessibility demand for certain services becomes crucial for responsible and 'smart' urban planning and infrastructure investment. In this study, we investigate how projected population change could affect accessibility to essential services in the City of Surrey, one of the fastest growing cities in Canada. Our objectives are two-fold: first, to quantify the additional pressure that Surrey's growing population will have on existing facilities; second, to investigate how changes in the spatial distribution of different age and income groups will impact accessibility equity across the city. We evaluated accessibility levels to healthcare facilities and schools across Surrey's multimodal transport network using origindestination matrices, and combined this information with high-resolution longitudinal census data. Paying close attention to two vulnerable population groups - children and youth (0-19 years of age) and seniors (65+ years of age) - we analyzed shifts in accessibility demand from 2016 to 2022. The results show that population growth both within and outside the catchments of existing facilities will have varying implications for future accessibility demand in different areas of the city. By 2022, the city's hospitals and walk-in clinics will be accessible 
to $\sim 9,000$ and $\sim 124,000$ more people (respectively) within a predefined threshold of 30 minutes by public transport. Schools will also face increased demand, as $\sim 8,000$ additional children/youth in 2022 will move to areas with access to at least half of the city's schools. Conversely, over 27,000 more people - almost half of them seniors - will not be able to access a hospital in under 30 minutes by 2022 . Since low-income and senior residents moving into poorly connected areas tend to be more reliant on public transport, accessibility equity may decline in some rural communities. Our study highlights how open-source data and code can be leveraged to conduct in-depth analysis of accessibility demand across a city, which is key for ensuring inclusive and 'smart' urban investment strategies.

Keywords: smart cities, transportation, origin-destination matrix, open-source data, equity

\section{Highlights}

- We quantify how population change will affect accessibility to education and healthcare facilities in Surrey, Canada, a growing smart city.

- Origin-destination matrices were combined with census data to map accessibility for two vulnerable populations (children/youth and seniors) in 2016 and 2022.

- Projected population growth both within and outside catchments of existing facilities will have varying implications for future accessibility demand.

- Low-income and senior residents moving into poorly connected areas may be more reliant on public transport, so accessibility inequity could increase.

- Open-source data and code can help quantify urban accessibility metrics, thus ensuring inclusive and 'smart' infrastructure investment.

\section{Introduction}

Cities are home to a majority of the world's population and concentrate most of the economic and infrastructural resources that sustain human wellbeing. Cities and infrastructure will drive the majority of human development for the foreseeable future, with rapid innovation in advanced information and communication technologies (ICT) enabling cities to be cleaner, smarter and potentially more inclusive and equitable (Thrift, 2014; de Jong et al., 2016). There is increasing potential for rapid ICT innovation, in combination with new citizen-generated 
data, to improve the planning and design of cities, which in turn can help address sustainable development needs (UNCTD, 2015).

The aspiration for universal access to essential services, such as healthcare, education, and mobility is at the core of the United Nations Sustainable Development Goals (SDGs) (UN, 2015). Although urban hubs are becoming more interconnected due to physical (roads) and virtual (internet) infrastructure investments, disparities persist in access to opportunities and essential services. These disparities are potentially related to both socioeconomic and physical factors, such as household income, education, social status, transport infrastructure and the spatial distribution of cities. However, the causal relationships between those factors and the resulting impacts upon livelihoods and development are not well understood (Hickford et al., 2015; Weiss et al., 2018, UN, 2015). Although low-income and low-resource countries are a primary focus for improvements under the SDG framework, accessibility inequalities continue to exist even within the most economically developed countries (Neutens, 2015). Here we apply new urban spatial analysis methods based on open-source public transport data and high-resolution neighborhood level census data to provide new insights for urban transport planning and accessibility.

Definitions and measurements of accessibility remain widely debated, and have been comprehensively reviewed in the literature (Kwan, 1998; Geurs \& van Wee, 2004; Vandenbulcke et al., 2009; Neutens et al., 2010). In a broad sense, accessibility describes the ease with which people can reach places or opportunities (an 'origin-oriented' or 'active' definition), or how easily a place or opportunity can be reached by people (a 'destinationoriented' or 'passive' definition) (Papa \& Coppola, 2012). Both these concepts of accessibility help to unravel complex linkages between land use, transport and human activity, and are an important feature of both urban and rural development policies (Neutens, 2015). For this study, we define accessibility as the extent to which individuals are able to reach out-of-home activities to satisfy basic needs including healthcare and education. We therefore focus on the ease of reaching valued destinations, rather than examining 'mobility' - observed travel behavior along the transportation network itself (El-Genedy \& Levinson, 2011).

An important lens to assess accessibility is through equity, which refers to the provision of sufficient opportunities to individuals for them to enjoy full and healthy lives (Neutens, 2015). The related, but subtly different, concept of equality implies providing the same opportunities to everyone (Neutens et al., 2010). Given that individuals differ widely in their socioeconomic and demographic backgrounds, a spatially and demographically differentiated approach is 
used to account for the diversity of needs in an urban transport system, and thus to work towards achieving equitable accessibility (Goddard \& Smith, 2001; Geurs \& van Wee, 2004; Neutens, 2015; Pereira et al., 2017).

Equity in accessibility has notably been investigated in the context of healthcare and schooling, as these are viewed as fundamental rights in many countries (Apparicio et al., 2008). Poor accessibility to healthcare has been shown to contribute to decreased uptake of preventative services, lower healthcare utilization and poorer health outcomes in both emerging and advanced economies (Gage \& Calixte, 2006; Hiscock et al., 2008; Dai, 2010) Within countries, differences in health status between disadvantaged social groups and their more advantaged counterparts have also been linked to disparities in healthcare accessibility (e.g. Kawakami et al., 2011; Bissonnette et al., 2012). Moreover, in contemporary Western societies, declining fertility rates and increased longevity are contributing to major demographic shifts to more elderly, less mobile populations (Lutz et al., 2008). This emerging phenomenon presents a major challenge for ensuring equitable healthcare accessibility across populations in an efficient and cost-effective manner (Loo et al., 2012; Neutens, 2015).

Previous studies have related spatial variability in accessibility to socioeconomic and demographic factors at a variety of scales. At the global scale, Weiss et al. (2018) used an innovative method to calculate accessibility to urban centres, by combining a variety of GIS datasets with a 'friction surface' based on least-cost-paths computed in Google Earth Engine. The authors found that accessibility to cities varied by wealth, with $90.7 \%$ of populations in high-income countries living within an hour of a city, compared to $50.9 \%$ in low-income countries. In a national-scale study of New Zealand, Hiscock et al. (2008) used GIS-based network functionality to relate access to healthcare facilities to socioeconomic data across all the country's census tracts. They reported that longer travel times in rural areas were related to reduced utilization of clinics and pharmacies, which has implications for accessibility equity along rural-urban divides. At the megacity scale, Pereira (2018b) found that new transport investments for large sporting events, combined with simultaneous rescheduling of the bus system, resulted in accessibility benefits accruing principally to middle- and higher-income groups, thereby reinforcing existing patterns in spatial inequality.

In this paper, we analyze accessibility to school and healthcare services within the City of Surrey, Canada, as an example of a fast growing, relatively affluent city in a high-income country. Like many modern cities around the world, Surrey faces challenges associated with rapid urban development, and in response, is positioning itself as a global smart city to improve 
urban livability, workability and sustainability. For instance, Surrey published a new Sustainability Charter in 2016 containing key sustainability outcomes to reach over the next 40 years (City of Surrey, 2016). A key part of this strategy is investing $\$ 238$ million in infrastructure over the period 2017-2021 (City of Surrey, 2017). However, transport investments may not have the desired impact if they are not optimally directed for ensuring equitable access to services (van Wee \& Geurs, 2011; Lucas et al., 2015; Hickford et al., 2015; Otto et al., 2016).

Our objectives for this study are two-fold. First, we quantify the additional pressure that will be placed on existing school and healthcare facilities as Surrey continues to grow economically and demographically. Second, we examine the potential effects that shifts in the spatial distribution of population and income may have for accessibility equity across the city. We perform longitudinal analysis to identify changes between 2016 and 2022, focusing on two vulnerable sub-populations (children/youth and seniors) that are often marginalized by highcapital investment and thus require particular attention when devising transport policies (Darcy, 2003). By mapping the potential accessibility of these populations to schools and healthcare facilities, we highlight the geographical areas that may experience increased accessibility demand in the future.

The remainder of this paper is presented in five parts. The next section introduces the socioeconomic context of the City of Surrey. Section 3 outlines the data sources and methodology used for the analysis, while section 4 presents our analysis and a discussion of the results. Section 5 summarizes the main conclusions of this paper.

\section{City case study}

\subsection{Demographic profile}

The City of Surrey is one of the largest cities in British Columbia, and is part of the regional district of Metro Vancouver, which itself is comprised of 23 local authorities. Surrey covers a total of $316 \mathrm{~km}^{2}$, and is composed of seven planning areas (6 communities and the City Centre) (Figure 1). The city's population increased by $37 \%$ over the period 2001-2016 to 520,000 , and its population is projected to increase by a further 300,000 by 2041 , making it the fastest growing city in Metro Vancouver (City of Surrey, 2013). 
The rapid growth in Surrey's total population masks differential patterns within its demographic profile. Although the city has the largest absolute population of children and youth (0-19 years of age), and thus the largest school district in Metro Vancouver, the proportion of children and youth has fallen steadily from 29.7\% in 1996 to 23.6\% in 2016 (Statistics Canada, 2017). Simultaneously, child poverty has increased over recent years, with $25 \%$ of children under the age of six now living in relative poverty. This mirrors a trend of increasing early childhood vulnerability: the Early Childhood Development Instrument (EDI), a questionnaire-based method for assessing 5-year olds' development, suggests that more children started school with vulnerabilities in Surrey's most recent testing in 2013 to 2016 compared to the previous round in 2011 to 2013 (Human Early Learning Partnership, 2016). The EDI is considered a good predictor of health, education and social outcomes in adolescence and adulthood. Increased vulnerability among today's child population could have significant impacts on their future well-being.

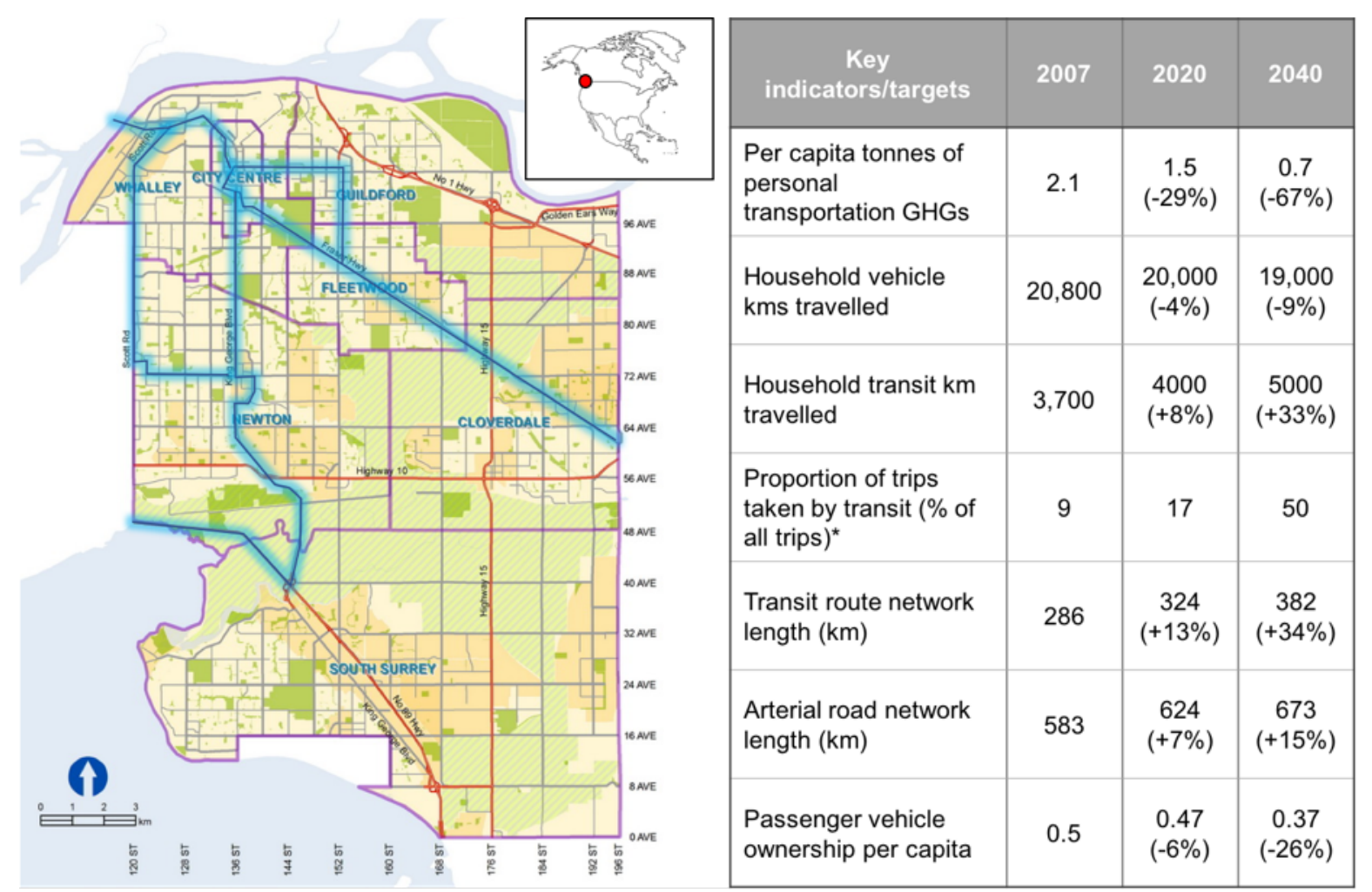

Figure 1 Location map of the City of Surrey, showing its seven planning areas (Whalley, Guildford, Fleetwood, Newton, Cloverdale, South Surrey and City Centre). Routes highlighted in blue represent the key components of the Frequent Transit Network (FTN). Inset map shows continental context. Table displays key indicators and targets for Surrey's transport strategies. *The 2020 and 2040 targets are based on regional targets, as Surreyspecific targets are not available for this indicator. (Map and table adapted from City of Surrey, 2014). 
While the share of children and youth has declined, the proportion of seniors (65+ years of age) in Surrey has increased from 10.3\% in 1996 to 13.9\% in 2016 (Statistics Canada, 2017). This is in part due to Surrey receiving 2000 new senior immigrants between 2000 and 2010, the second largest number in the province after the City of Vancouver (City of Surrey, 2012). In total, Surrey is home to $18.8 \%$ of the region's senior population, yet only contains $11 \%$ of its senior services. This aging trend could have important implications for transport planning in the city, because as they get older, seniors tend to drive less and become increasingly dependent on public transport (Lutz et al., 2008; Ryan et al., 2015).

\subsection{Transportation in Surrey}

There are marked differences in the way different population groups use transportation to move around the Surrey. More than 100,000 people use the public transportation system in the city at least semi-regularly (City of Surrey, 2014). However, transit usage varies across the city as a function of service provision and distance: $31.26 \%$ of City Centre residents use public transit to get to work, whilst only $7.2 \%$ of South Surrey residents and $5.4 \%$ of Cloverdale residents do so. Overall, $12.8 \%$ of employed Surrey residents use public transit to get to work; the vast majority $(76.8 \%)$ travel to work in private vehicles (City of Surrey, 2012). The large number of vehicle kilometers travelled in Surrey (see table in Figure 1) contributes to transportation emissions per capita being 38\% greater than the Metro Vancouver average (City of Surrey, 2014).

The development of Surrey's Frequent Transit Network (FTN; Figure 1) has been a key aspect of the City's strategy to increase use of public transit, especially for residents living further away from the City Centre. The FTN corridor provides transit service at least every 15 minutes in both directions throughout the day and into the evening. Whilst FTN routes in Surrey have better on-time performance and speeds compared to wider Metro Vancouver, the routes also have lower employment density, fewer passenger boardings, and thus higher costs per passenger (City of Surrey, 2014). Furthermore, only $7.5 \%$ of the entire regional FTN is located within Surrey, despite the City being home to over $20 \%$ of Metro Vancouver's population.

Surrey plans to finance a proportionally larger increase in the length of the transit route network compared to the arterial road network (see table in Figure 1). This signals an intention to decrease the number of private vehicle kilometers travelled whilst increasing the capacity 
of public transportation, which reflects the province-wide target for the share of total trips taken by transit to increase to $17 \%$ by 2020 , and $50 \%$ by 2040 .

\section{Methods}

As discussed in section 1, we define accessibility as a characteristic of the ease with which a destination can be reached by a variety of social groups. In order to capture the impact of socioeconomic and demographic shifts in Surrey on accessibility, we examined changes to two key population groups from 2016 to 2022: children and youth (0-19 years of age) and seniors (65+ years of age). We focused our accessibility analysis on two facility types: healthcare facilities (hospitals and walk-in clinics) and schools. These facilities were chosen because of the essential roles they play in satisfying an individual's basic needs.

Catchment area analysis was used to estimate the number of people from different demographic groups that could reach the relevant facilities from their homes within a certain travel time threshold. We carried out this analysis for two main transport modes: (i) private vehicles (cars) only; (ii) optimal combination of public transportation (bus and rail) and walking.

\subsection{Data sources}

We relied on a variety of open data sources (Table 1) and open-source code, which are becoming more prevalent as part of the broader smart cities movement, to emphasize the transferability of our methods and analysis for other comparable city case-studies.

Canadian census data on Surrey's resident population were used to assess population counts and characteristics (age and income) at the Dissemination Area (DA) level. A DA is the smallest standard geographic unit for which all census data are disseminated and is usually composed of 400 to 700 residents (Statistics Canada, 2017). Census data were acquired via SimplyAnalytics, a web-based mapping and data analysis application. Specifically, we used the DemoStats database (SimplyAnalytics, 2017a) to obtain current-year estimates of socioeconomic and demographic data for 2016 , and projections for 2022 . These dates were chosen because 2016 was the most recent complete census dataset available to us, and 2022 was the latest projected dataset available. DemoStats combines econometric, demographic and 
geographic models, and employs a variety of data sources, including the latest census, current economic indicators, post-censal estimates from federal and provincial governments, immigration statistics and economic data (SimplyAnalytics, 2017b). As such, the 2022 projections used in this study should be viewed as only one possible scenario of future population.

Once acquired, the Dissemination Area-level census data were spatially reorganized into a grid of 1,480 equally sized hexagons (500 m diagonal diameter; $0.16 \mathrm{~km}^{2}$ ), which covered the entire surface area enclosed by Surrey's city boundaries. Hexagon cells were used to reduce sampling bias from edge effects. Section 3.2.1 outlines how census data were assigned to each hexagon.

\begin{tabular}{|l|l|l|l|}
\hline Data & Details & Source & Year \\
\hline $\begin{array}{l}\text { Population } \\
\text { count / socio- } \\
\text { economic } \\
\text { characteristics }\end{array}$ & $\begin{array}{l}\text { Dissemination } \\
\text { Area (DA) } \\
\text { level }\end{array}$ & - StatsCanada Census, via SimplyAnalytics & $\begin{array}{l}2016, \\
2022 \\
\text { (projected) }\end{array}$ \\
\hline Public schools & $\begin{array}{l}\text { Location and } \\
\text { facility type }\end{array}$ & $\begin{array}{l}\text { - DataBC (British Columbia Open Data catalogue) } \\
\text { - Surrey Open Data catalogue }\end{array}$ & 2014 \\
\hline Hospitals & $\begin{array}{l}\text { Location and } \\
\text { facility type }\end{array}$ & $\begin{array}{l}\text { - DataBC (British Columbia Open Data catalogue) } \\
\text { - Surrey Open Data catalogue }\end{array}$ & 2017 \\
\hline Walk-in clinics & $\begin{array}{l}\text { Location and } \\
\text { facility type }\end{array}$ & $\begin{array}{l}\text { - DataBC (British Columbia Open Data catalogue) } \\
\text { - Surrey Open Data catalogue }\end{array}$ & 2017 \\
\hline Street network & $\begin{array}{l}\text { Roads and } \\
\text { pedestrian } \\
\text { network }\end{array}$ & - Open Street Maps & 2017 \\
\hline $\begin{array}{l}\text { Public } \\
\text { transport } \\
\text { system }\end{array}$ & $\begin{array}{l}\text { Geolocated } \\
\text { timetables } \\
\text { organized in } \\
\text { GTFS format }\end{array}$ & - Translink (Metro Vancouver) & 2017 \\
\hline
\end{tabular}

Table 1 Open Data sources used in this study. The General Transit Feed Specification (GTFS) is a common format for public transportation schedules and related geographic information. TransLink is Metro Vancouver's regional authority for public transport.

Data on the location and type of facilities (schools and healthcare services) were acquired from British Columbia's Open Data catalogue, supplemented by data from Surrey's Open Data catalogue where available (Figure 2). In British Columbia's public school system, three tiers of schooling exist: elementary (ages 6-12), junior high (ages 12-15) and high (ages 15-18). In our dataset, the junior high and high school levels were combined together as 'secondary' education. Where schools provided education at both elementary and secondary levels, they were included in the accessibility analysis for both levels. Only the 104 schools (79 elementary, 8 mixed elementary-secondary, 17 secondary) registered as open to students in the most recent year available in the open-source dataset (2014) were considered in our analysis. We treated persons aged $0-19$ as a single group, because the age categories 
reported by Statistics Canada do not match up with the elementary/secondary age divide, which precludes us from confidently attributing pupils to their correct schooling level. Instead, we use the 'children/youth' category to provide a general sense of the potential pressures for places that schools may face in the years around our study period.

In the case of healthcare services, we differentiate between 'hospitals' and 'walk-in clinics'. Hospitals are medical institutions providing diagnostic and treatment services for people whose illnesses/injuries require bed occupation for at least one night, and are generally distinguished by specialism and the level of care on offer (e.g. general acute, subacute, extended acute). Walk-in clinics provide treatment services for people with minor illnesses/injuries that do not require a visit to a hospital emergency department or urgent care facility. In total, our analysis included 2 hospitals and 33 walk-in clinics. Two other hospitals, located in the city of New Westminster to the northwest and in Langley to the southeast, are potentially accessible to some of Surrey's residents but falls outside the city's jurisdiction and investment strategy.

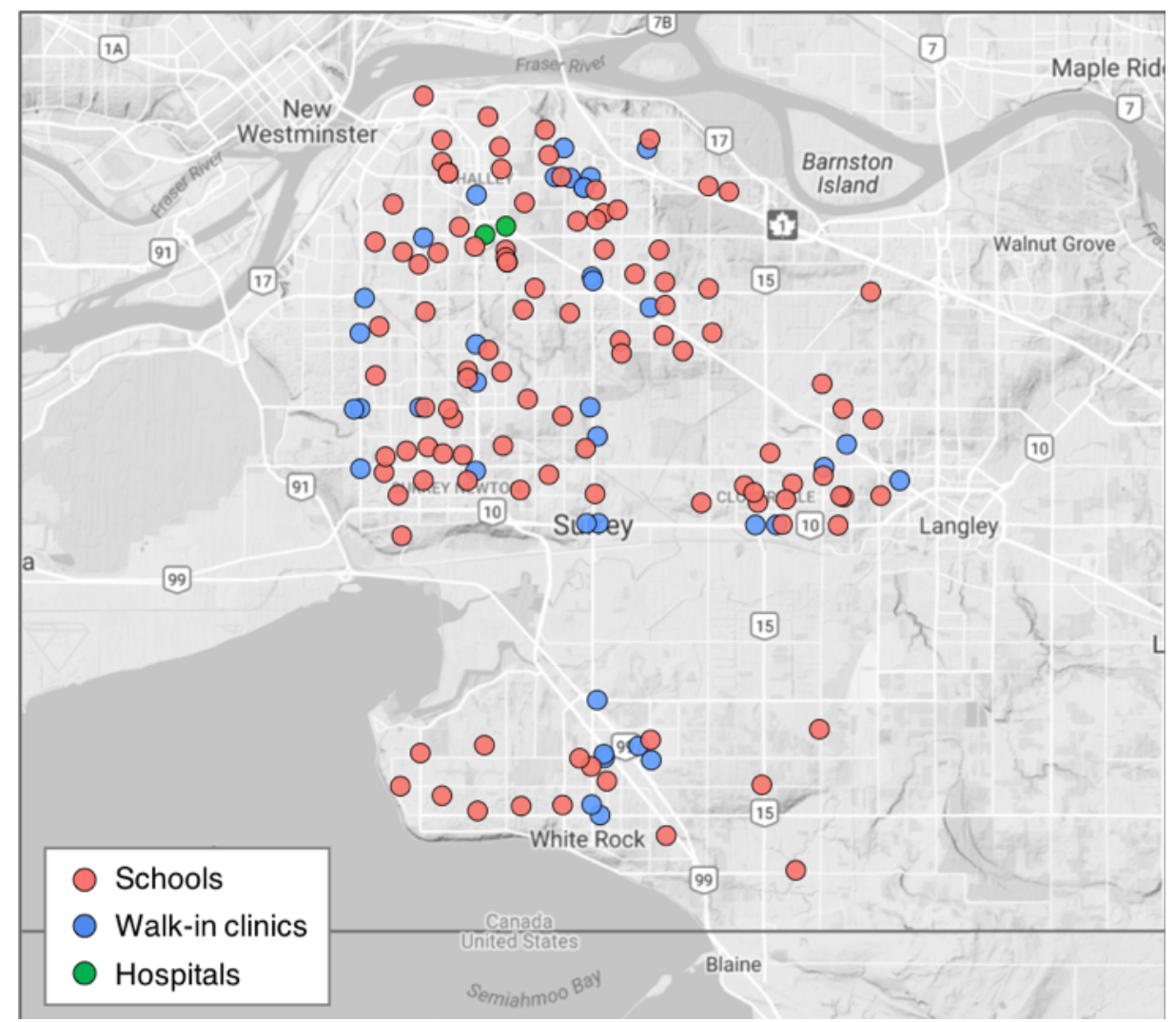

Figure 2 Spatial distribution of facilities analyzed in this study: schools, walk-in clinics and hospitals. 
The spatial layout of road networks and pedestrian infrastructure was acquired from OpenStreetMap; this was the basis for the routing algorithm used to analyse travel times for walking and private vehicle driving (see section 3.2.2). Routing for public transportation was supplemented by data from Translink's geolocated timetables of routes and stops for all public transit modes from September 2017. These data are organized in General Transit Feed Specification (GTFS) format, which represent actual timetabling but do not account for congestion levels across the city.

\subsection{Data analysis}

\subsubsection{Assigning census data to grid cells}

We first reorganized the census data into a grid of hexagonal cells covering the entire area of the city. The centroid of each hexagonal cell was intersected with the DA polygons to determine spatial collocation, and the DA census data were assigned to their appropriate hexagonal cells. DA polygons were typically larger than the hexagonal cells in our case, so census data had to be shared or split (depending on data type) across multiple hexagonal cells. For averaged or proportional data (e.g. income, age), we assigned the same value to all cells from the same DA. In contrast, population counts are discrete data, so must be divided among constituent cells. For each DA, we divided its total population equally among all the hexagonal cells whose centroids corresponded with that DA. For example, if the total population count of seniors within a particular DA was 200 people, and 10 hexagonal cells fell within that DA, each cell would be assigned a senior population of 20 people. This downscaling method is simple to implement and does not make assumptions about how populations are distributed according to land use. However, in some instances, cells may be mainly composed of infrastructure or farmland, so in reality may not be able to host a significant population increase. Detailed models of land-use change can be used to estimate heterogeneous population downscaling (e.g. Meiyappan et al., 2014), but such an approach is beyond the scope of our study.

Income data are reported categorically by Statistics Canada, into 16 income groups defined by upper and lower income bounds (the highest income level $(\$ 250,000)$ is unbounded on one side). We used income data to perform income distribution analysis (based on 'low', 'medium' and 'high' income categories). In order to define appropriate income banding, we estimated income quintiles for the entire City of Surrey using the categorised income data for all 165,477 
households in the census. Following Statistics Canada (2017), a household was considered low-income if it is in the bottom $20 \%$ of the income distribution, medium-income if it is within $20-80 \%$ of the income distribution, and high income if it is in the top $20 \%$ of the income distribution. We inferred the appropriate banding values for the three income categories in both 2016 and 2022, to control for earnings inflation over time. Low household income was defined as $<\$ 40,000$ (for 2016) and $<\$ 50,000$ (for 2022), medium household income as $\$ 40,000-\$ 150,000$ (2016) and \$50,000-\$175,000 (2022), and high household income as $>\$ 150,000(2016)$ and $>\$ 175,000(2022)$.

\subsubsection{Calculating origin-destination matrices}

Once the domain grid was layered with census data, travel-time estimates were computed between every pair of grid cells (an 'origin' and a 'destination') to derive a map of accessibility across the city. We calculated the travel-time matrices using OpenTripPlanner (OTP, 2017), an open-source routing engine called within the travel-time matrix algorithm of Pereira (2017). For two main modes of transport (private vehicle only, and an optimal combination of public transportation and walking), 36 travel-time matrices were estimated for a typical working day (Tuesday, $19^{\text {th }}$ September 2017), with departures every 20 minutes between 7 am and $7 \mathrm{pm}$. We derived an average travel-time estimate for each pair of grid cells across all 36 resulting matrices, thus accounting for fluctuations in service availability throughout the day. In the public transport/walking mode, OTP routing considers walking time from the point of origin to the transit stop, waiting time for the vehicle, actual travel time through the transport network and eventual transfers, and the walking time from the transit stop to the final destination.

The OTP routing engine used in this study does not account for traffic congestion levels, which can slow travel times predictably (e.g. at rush hour) and unpredictably (e.g. during traffic accidents). Instead, we consider accessibility via private driving based on road layout and speed limits, and accessibility via public transportation based on current service timetabling in the GTFS dataset. This approach may overestimate service performance in some areas and at specific times of the day. Our accessibility figures represent a general estimate of accessibility during normal travelling hours, without adverse conditions. While beyond the scope of the current paper, future studies could incorporate vehicle GPS data to generate higher resolution estimates of travel-time (e.g. Wessel et al., 2017). 


\subsubsection{Catchment area analysis}

In order to estimate the number of residents that could reach the schools and healthcare facilities within a specified cut-off travel time, we applied a modified version of the isochronic or cumulative-opportunity measure (Wachs \& Kumagai, 1973; Neutens et al., 2010; Pereira, 2018b). Accessibility was evaluated from the perspective of both the origin (i.e. the 'active' accessibility of a population towards a facility) and the destination (i.e. the 'passive' accessibility of the facilities with respect to the population) (Papa \& Coppola, 2012). Active accessibility for each origin grid cell (for a total $n$ grid cells) was calculated as:

$$
\begin{gathered}
F_{o, T}=\sum_{d=1}^{n} F_{d} f\left(t_{o d r}\right) \\
f\left(t_{o d r}\right)=\left\{\begin{array}{l}
1 \text { if } t_{o d r} \leq T \\
0 \text { if } t_{\text {odr }}>T
\end{array}\right.
\end{gathered}
$$

Equation 1

where $F_{o, T}$ is the number of facilities $F$ that can be reached from origin $o$ within time threshold $T, F_{d}$ is the number of facilities in destination cell $d$, and $f\left(t_{o d r}\right)$ is a time threshold function whose value (either zero or one) depends on whether travel time $t_{\text {odr }}$ is greater or smaller than time threshold $T$.

Passive accessibility for each destination grid cell was calculated as:

$$
\begin{gathered}
C_{d, x, T}=\sum_{o=1}^{n} P_{x o} f\left(t_{o d r}\right) \\
f\left(t_{o d r}\right)=\left\{\begin{array}{l}
1 \text { if } t_{o d r} \leq T \\
0 \text { if } t_{\text {odr }}>T
\end{array}\right.
\end{gathered}
$$

Equation 2

where $C_{d, x, T}$ is the catchment size of destination $d$ for population of characteristic $x$ (e.g. age, income) within time threshold $T$, and $P_{x o}$ is the number of people with demographic characteristic $x$ in origin $o$.

Time thresholds for cumulative opportunity measures should be based on a reasonable maximum amount of time most people may be willing to travel to reach key activities (Boisjoly \& El-Geneidy, 2017), yet identifying such thresholds remains an open question in the literature. Universal boundaries for acceptable travel times are difficult to estimate, as they are known to vary according to travel mode as well as socioeconomic, demographic and lifestyle factors (Mokhtarian \& Salomon, 2001; Guagliardo, 2004; Milakis et al., 2015; Neutens, 2015). 
In a comprehensive analysis of 32 recent metropolitan transport plans from North America, Europe, Australia and Asia, Boisjoly \& El-Geneidy (2017) found that most plans use time thresholds of 30-40 minutes when considering accessibility to schools and hospitals via public transit. For the sake of simplicity, we set our travel time threshold $T$ to 30 minutes for both the active and passive accessibility cases. The cumulative opportunity measure has other limitations apart from the arbitrariness of the time threshold. It does not account for the size (or 'attractiveness') of the destination, nor the impedance (or 'friction') of travel time, cost and effort beyond the binary threshold variable. However, in comparison with other commonly used metrics, the cumulative-opportunity measure makes few assumptions about user behavior and preference, and is easily interpreted (Geurs \& van Wee, 2004; Neutens et al., 2010).

It is useful to consider the competitive nature of accessibility, especially in cases where there is a finite usable supply of a facility (van Wee et al., 2001). Competition measures incorporate the demand potential for facilities by dividing the supply by demand through various methods (Wilson, 1971; Weibull, 1976; Shen, 1998; van Wee et al., 2001). The main assumption made in traditional competition measures is the value of the opportunity, which is further assumed to be equal for all origin members (Geurs \& van Eck, 2003). Both schools and healthcare services are subject to competition effects and have capacity constraints, but there are difficulties in applying the principles of competition measures. In the case of healthcare services, there is a temporally variable dimension to the demand, such that not all residents need to use a hospital or clinic at once (Delmelle \& Casas, 2012). In the case of schools, it is difficult to make assumptions about the values different parents rely on to choose where to send their children (within the constraints of school catchments).

In order to provide illustrative analysis of competition in our study, we propose a new simple hybridised 'competitive' version of cumulative opportunity accessibility, which combines both active and passive accessibility metrics. The competition-based accessibility $\left(H_{O, T}\right)$ is defined as the sum of the inverse of the catchment size $C_{d, x, T}$ for each facility that can be reached from each origin cell:

$$
H_{o, T}=\sum_{d=1}^{F_{o, T}} \frac{1}{C_{d, x, T}}
$$


As an illustration, this metric captures competition for classroom seats by dividing all the schools that can be reached from location $i$ (active accessibility component) by the entire population that could potentially reach those same schools (passive accessibility component). Whilst the resulting metric is not as intelligible as a cumulative opportunity measure, it does intuitively show the relative competition for school places or hospital/clinic beds across the city by considering both the number of accessible facilities and potential competing demand for those facilities. For instance, an origin cell with (active) access to five walk-in clinics, each of which can be accessed (passively) by 10,000 people, will have higher competition-based accessibility than a cell with access to ten walk-in clinics, each of which can be accessed by 100,000 people. However, this approach does not account for actual capacity (i.e. the number of beds or school places available in reality), as it was not possible for us to acquire this information from open sources. Including capacity data would increase the value of our metric for planning purposes. The assumptions made in our competition-based accessibility measure are the same as for traditional cumulative opportunity measures.

We acknowledge that numerous other accessibility measures exist in the literature, including gravity-based (Hansen, 1959) and place rank measures (El-Geneidy \& Levinson, 2011). We consider the limitations of these alternative models, which we argue make them inappropriate for use in our study. Gravity-based models are commonly used because they partly account for impedance. However, they rely on a relatively generic distance decay function and an 'attractiveness' parameter, which to be of use must be robustly validated using empirical data rather than arbitrarily defined (Guagliardo, 2004). Moreover, gravity-based models output values that are difficult to interpret as constituting high versus low accessibility, thus making comparisons between cases with different units of attraction challenging (Delmelle \& Casas, 2012). This limitation can be partly overcome through standardization, but information is then lost on the absolute number of facilities each resident can access (and conversely the absolute number of residents that can access each facility). Place rank measures were developed to address the issue of origin members not valuing opportunities and facilities at destinations equally - as is often assumed in competition measures (El-Geneidy \& Levinson, 2011). Inspired by webpage ranking methods in large search engines, place rank uses relative attractiveness ranks of zones in a region. The method therefore requires knowledge of true origins and destinations, and as such is more a reflection of people's actual travel behaviour than of the places and opportunities they could potentially reach using the transport system. This method is also computationally expensive due to the iterative calculations involved. Place rank acts to complement, rather than compete with, commonly used accessibility models. 
In this study, we are primarily interested in evaluating maximum theoretical accessibility, without imposing value judgements and thus potentially replicating biases in travel behaviour (Neutens et al., 2010). The assumptions required in gravity-based and competition measures are not appropriate in this regard. Further, indicators that are not directly interpretable in absolute units are difficult to communicate to policymakers, which reduces the potential impact of some of these findings (Neutens, 2015). In sum, we deem the modified cumulativeopportunity measure, and its competition-based derivative, to be most appropriate for our study objectives, and can implement the above methods for future studies.

Incorporating the explicit cost of travel is also not an objective of our study. The public transportation system in Metro Vancouver is run by a single operator, Translink. Surrey lies within a single 'travel zone' as defined by Translink, meaning that all transit journeys starting and finishing in Surrey cost the same price, including any transfers made within a 90-minute window from the start of the first journey (Translink, 2018). Since our catchment analyses are based on travel time cut-offs of 30 minutes, the price of using public transport is essentially fixed for an individual user. Private vehicles are not available to the entire population (e.g. as a function of age and income), so our private vehicle trip analysis is simply provided as a comparison to accessibility levels using public transportation. Consequently, incorporating private vehicle costs (mostly associated with fuel prices, repairs and vehicle depreciation) is beyond the scope of this study. Nonetheless, monetary costs of using public transport have been shown to influence individuals' accessibility (El-Geneidy et al., 2016) and issues of affordability should be more carefully considered in future studies.

\subsubsection{Longitudinal change}

We conducted the same analysis for 2016 and 2022. We kept the spatial distribution of the facilities and the distribution and timetabling of the transportation network constant for both years, but we changed the population and income distributions as appropriate using the projected population and income data. Surrey's City government plans to invest several hundred million dollars in infrastructure over the next few years (City of Surrey, 2017), and this will likely affect levels of service provision across the city. In particular, the planned construction of a Light Rail Transit in Surrey may alter the ease and speed of public transportation in some neighborhoods (Shirocca, 2015).

In the absence of reliable data on future changes to roads, transit routes and timetabling, we conducted our analysis on the assumption that the transport network remains unchanged 
between 2016 and 2022. We also assumed unaltered service provision because we did not have information on where future healthcare and schooling facilities are due to be built. The scope of our study is to isolate the effects of socioeconomic shifts between 2016 and 2022 on the size and composition of facilities' catchments, rather than projecting future service and transport provision to estimate absolute accessibility in the future. Indeed, our focus on accessibility demand could help inform where new transport services and educational and healthcare facilities should be allocated.

\section{Results and Discussion}

\subsection{Demographic and socioeconomic changes (2016-2022)}

Projected population change in Surrey over our study period is shown in Figure 3. Population change differs spatially and between age groups, but most areas will experience population growth between 2016 and 2022. The highest total growth rates are observed in parts of Fleetwood, Newton and South Surrey (Figure 3b). The number of children and youth, which made up $24.2 \%$ of Surrey's population in 2016 , is projected to increase by $\sim 8,000$ individuals by 2022 . This is a lower rate of increase $(7.5 \%)$ compared to the wider population $(10.1 \%)$, and occurs unevenly across the city, with rural areas experiencing low or even negative growth rates (Figure $3 \mathrm{~d}$ ). In contrast, the number of seniors, which made up $13.9 \%$ of the population in 2016 , is projected to increase by $\sim 20,000$ individuals by 2022 (a growth of $28.9 \%$ ). Growth in the senior population is more evenly spread across the city, with the highest growth concentrated in South Surrey, Guildford and the City Centre (Figure 3f). This is reflected in the significant increase in median age in these areas (Figure 3h).

Actual and projected spatial income distributions are shown in Figure 4. The lowest median household income levels for 2016 are located in Whalley, the City Centre, and rural parts of South Surrey, and the highest in urban South Surrey and Cloverdale (Figure 4a). This corresponds to concentrations of low-income (Figure 4e) and high-income (Figure 4i) housing, respectively. Medium-income households are widely distributed across the city (Figure $4 \mathrm{~g}$ ). Whilst median household income will rise by a city-wide average of $19.1 \%$ by 2022 (Figure $4 \mathrm{~b}$ ), the number of low-income (Figure 4f) and high-income (Figure 4j) households will increase unevenly in space. 

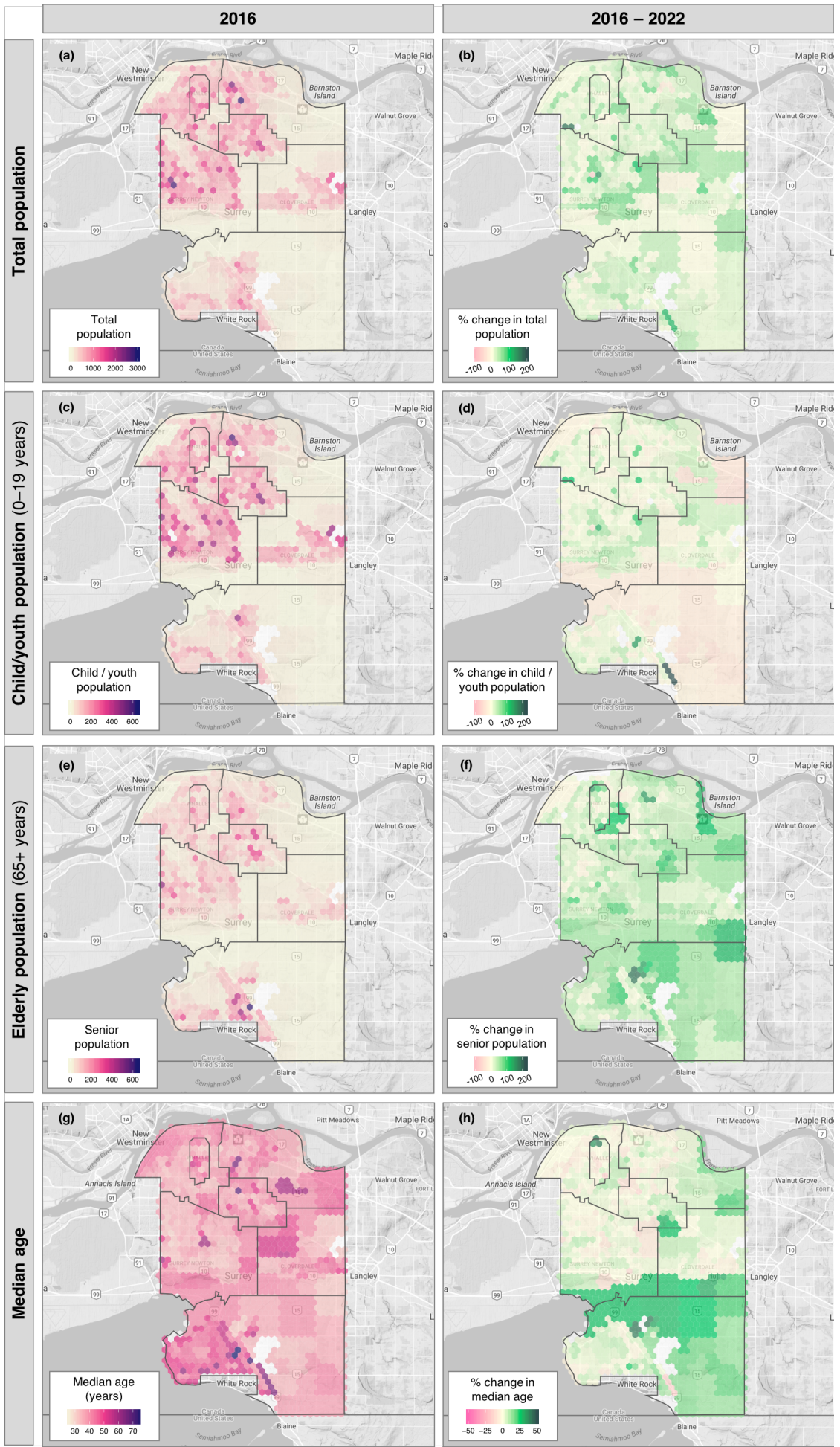

Figure 3 (a) Total population per grid cell in 2016; (b) \% change in total population from 2016 to 2022; (c) Children and youth population (0-19 years old) per grid cell in 2016; (d) \% change in children and youth population from 2016 to 2022; (e) Senior population (65+ years old) per grid cell in 2016; (f) \% change in senior population from 2016 to 2022; (g) Median age per grid cell in 2016; (h) \% change in median age from 2016 to 2022. White cells represent no data (e.g. uninhabited areas). 

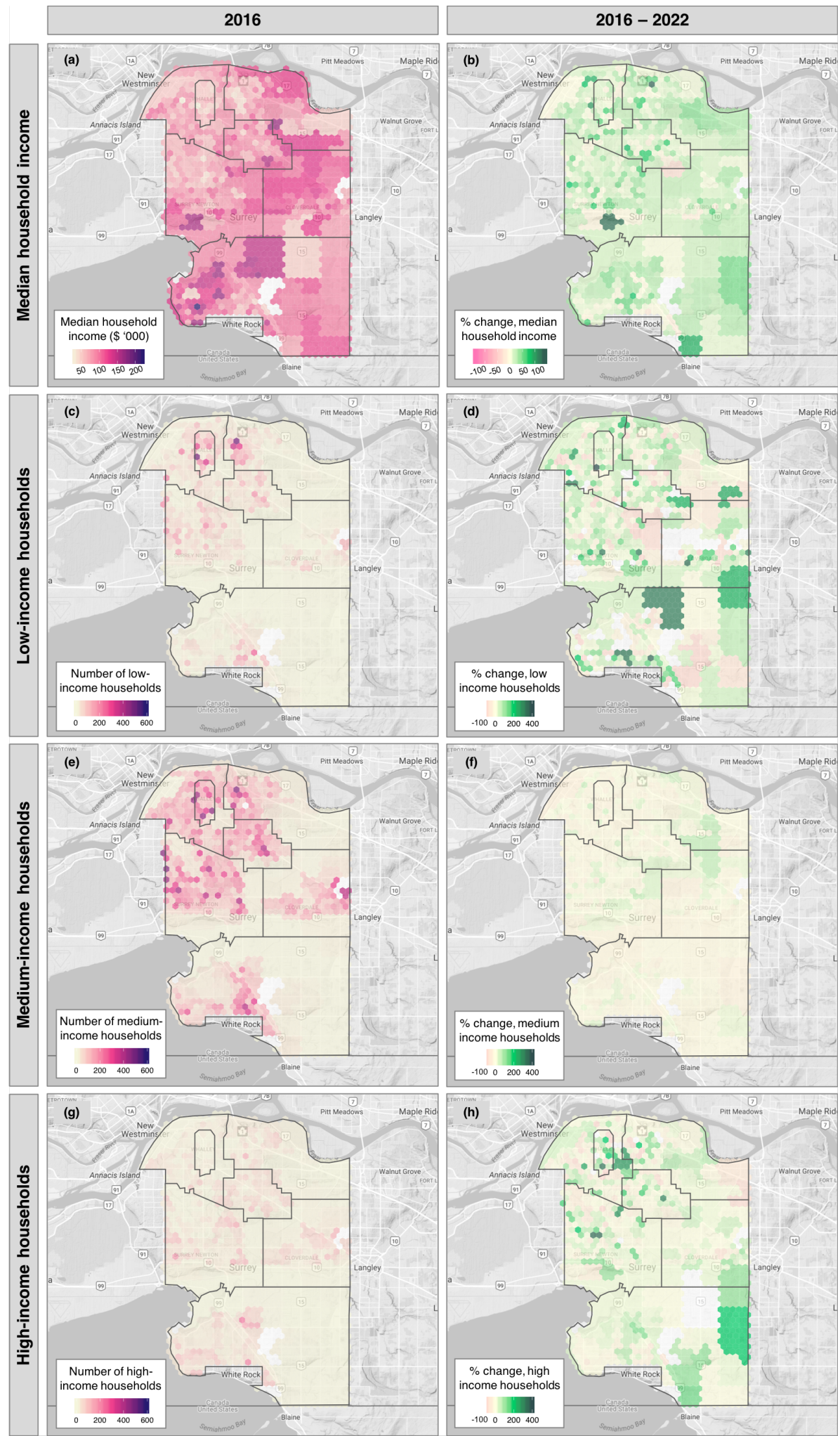

Figure 4 (a) Median household income in 2016; (b) \% change in median income from 2016 to 2022; (c) Number of low-income households in 2016; (d) \% change in number of low-income households from 2016 to 2022; (e) Number of medium-income households in 2016; (f) \% change in number of medium-income households from 2016 to 2022; (g) Number of high-income households in 2016; (h) \% change in number of high-income households from 2016 to 2022 . White cells represent no data. 


\subsection{General accessibility}

We quantify the general accessibility for each grid cell as the proportion of all other cells in the city boundary that can be reached within 30 minutes. This highlights the underlying geography of accessibility supported solely by the transport network, regardless of land use patterns. Based on this catchment area analysis, we found high general accessibility for all cells when the transportation mode is a private vehicle $(\bar{x}=57.9 \%, \sigma=11.8 \%)$. General accessibility is significantly lower and more variable for public transportation/walking mode $(\bar{x}=25.2 \%, \sigma=$ 15.1\%) (Figure 5a). Since accessibility is calculated using network-constrained walking distances and/or timetabled travel times, terrain with poor street connectivity (e.g. large parks, golf courses and farmland) results in pockets of very low accessibility in the immediate vicinity of well-connected areas. As can be expected, locations with the highest general accessibility are found along major transit routes served by a multitude of stops (Figure 5b). Areas with high concentrations of low-income households (e.g. Whalley/City Centre) and of high-income households (e.g. South Surrey) tend to contain large transport hubs, so the general accessibility of these income groups is proportionally high; medium-income households suffer from lower general accessibility on average, as they are distributed fairly evenly across the city's neighbourhoods.
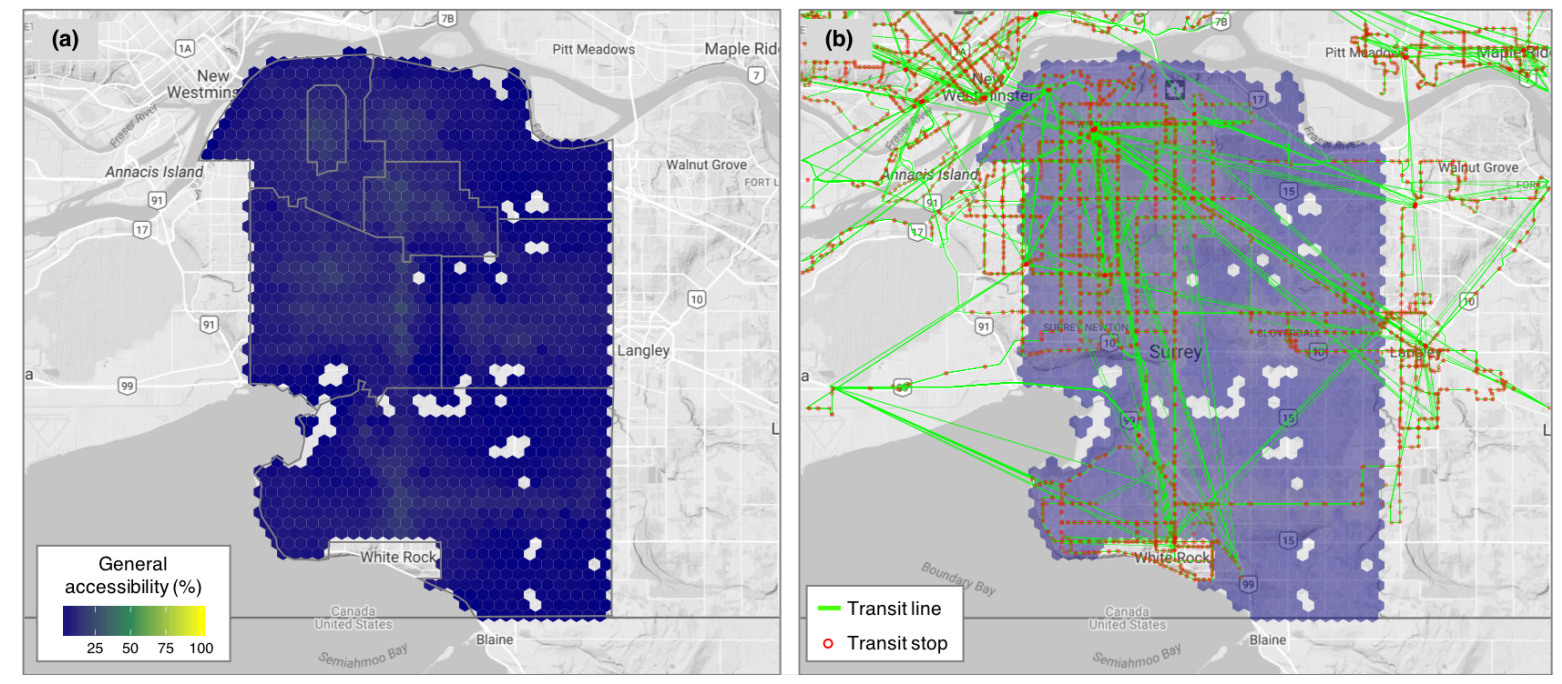

Figure 5 (a) General accessibility in Surrey (measured, for each origin cell, as a proportion of all other cells that can be reached within 30 minutes) for the public transport/walking mode; (b) Overlay of all Translink transit stops and lines in Surrey, and connections to neighbouring cities. 


\subsection{Schools and healthcare facilities}

The rapid changes in the demographic and socioeconomic makeup of Surrey will have marked impacts on patterns of potential accessibility demand for healthcare facilities and schools. The city will have to contend with two accessibility issues related to this growth: first, existing facilities will have a greater number of residents competing for services within their catchments, and second, a greater number of residents will be settling in zones with no current access to certain facilities. Both these issues are also intersected by shifts in income distribution. In the following discussion, we use the term 'accessible' to mean reachable using public transport/walking within our travel time threshold of 30 minutes.

\subsubsection{Origin-oriented accessibility}

The origin-oriented, or 'active', accessibility for each facility type is shown in Figure 6, in the form of spatially distributed maps and aggregated statistics. Accessibility to hospitals and walk-in clinics is highest in the urban core (Figure 6a,d), but fades to zero in the eastern and southern periphery of the city. Whilst the proportion of Surrey's population without access to a hospital or walk-in clinic (59.7\% and 4.8\% respectively) will change little from 2016 to 2022, the absolute increase in numbers is significant. Over 27,000 more people will have no access to a hospital, almost half of which will be seniors (Figure 6c). In income terms, 2700 more low-income households and $\sim 1480$ more high-income households will have no access to a hospital (Figure $6 \mathrm{~b}$ ). While $\sim 1,000$ of these include re-categorizations of households at the bottom end of the medium-income band in 2016 to low-income status in 2022, this still implies $\sim 3,180$ new households (primarily in Guildford and South Surrey) will be out of reach of a major healthcare facility. At the same time, population growth will result in over 7,000 more people having access to over half of the city's hospitals and almost 3,000 more for walk-in clinics (Figure $6 \mathrm{c}, \mathrm{f}$ ), which could create severe bottlenecks for existing healthcare services.

In terms of school facilities, spatial accessibility patterns are similar to those for walk-in clinics (Figure 6g,j). With 70,000 students, Surrey already has the largest school district in British Columbia. Schools appear to be relatively well distributed to serve the city's (proportionally shrinking) school-age population, with $>94 \%$ of all children/youth being able to reach at least one elementary or secondary school within 30 minutes on public transport. However, the school system is likely to face increased pressure from the $\sim 8,000$ additional children/youth expected by 2022 , the majority of which will move to areas with access to at least half of all schools in the city within 30 minutes by public transport (Figure 6i,I). Over 5,000 more low- 
income households will have access to at least one elementary and secondary school (Figure $6 \mathrm{~h}, \mathrm{k})$, although not all these households will contain school-age children.

A complementary measure of accessibility quantifies how quickly a resident can reach their nearest facility, which helps to identify 'hotspots' of active accessibility in the city. In. Figure 7 displays the travel time to the closest healthcare and school facility for each grid cell, both in spatial terms and in the form of cumulative frequency distributions per income group and year. the case of hospitals, cells with high median household incomes have much longer travel times (by 20-30 minutes per equivalent cumulative frequency) than low-income cells (Figure $7 b$ ), because of the hospitals' location in Whalley where lower-income DAs are prevalent. This differentiation will decrease by 2022 , as new low-income households settle further from the City Centre and some of the existing households at the bottom of 2016's medium-income bracket fall into low-income bracket in 2022. In the case of walk-in clinics and schools, medium-income areas generally have the longest average travel times to their facility, and this will continue to be the case in 2022 (Figure 7d,f,h). The cumulative frequency curves highlight how the expected expansion of low-income households in more rural suburbs, where transit lines and stops are less concentrated, will result in increased travel times to the nearest healthcare and educational facilities for low-income individuals. 

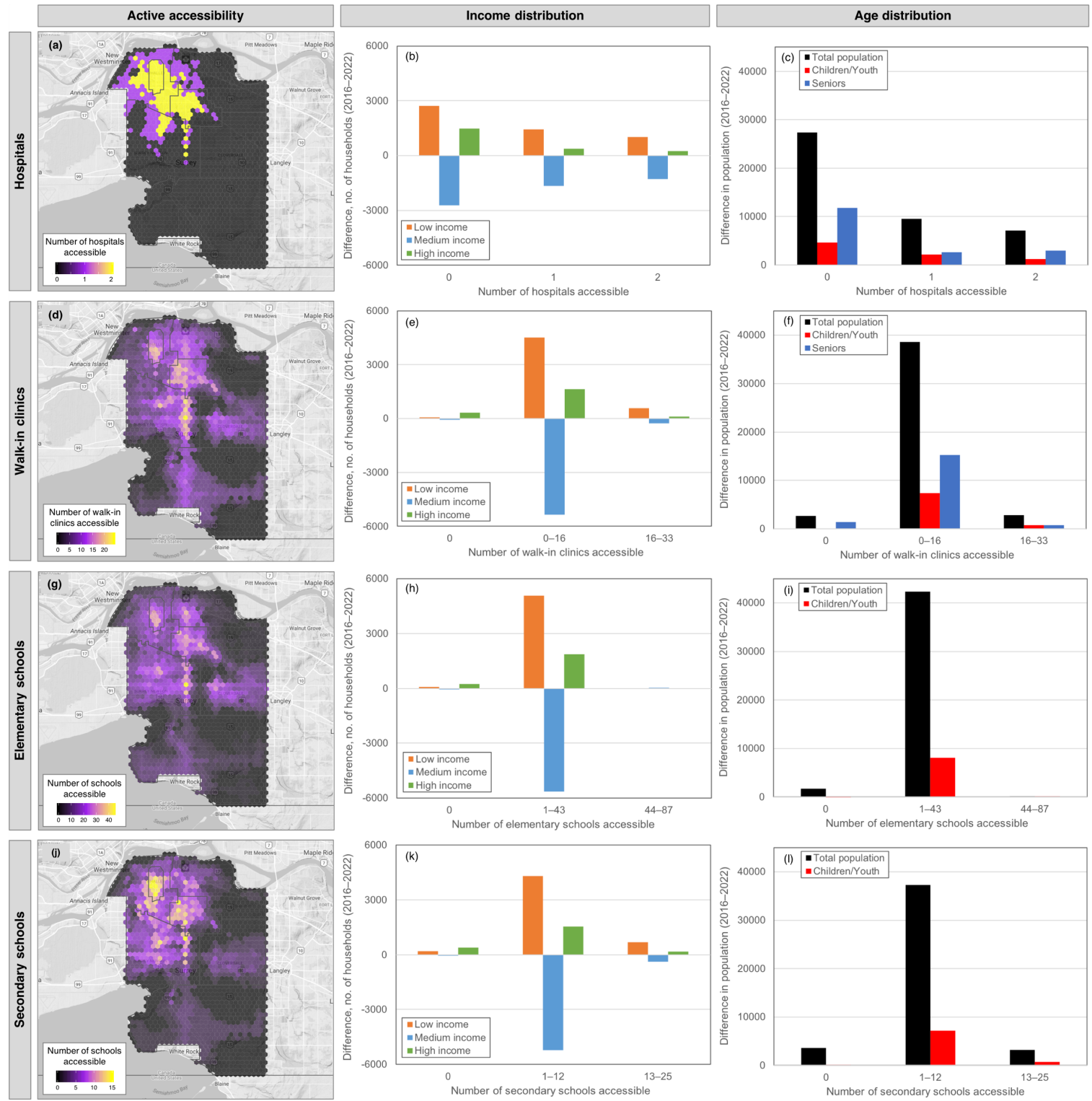

Figure 6 Origin-oriented ('active') accessibility in 2016, for a time travel threshold of 30 minutes by public transport/walking. Number of accessible facilities for (a) hospitals, (d) walk-in clinics, (g) elementary schools, (j) secondary schools. Difference (from 2016 to 2022) in the number of low-, medium- and high-income households with access to zero, up to half, and up to all facilities using public transport/walking, for (b) hospitals, (e) walk-in clinics, (h) elementary schools, and (k) secondary schools. Difference (from 2016 to 2022) in the number of residents by age group with access to facilities using public transport/walking, for (c) hospitals, (f) walk-in clinics, (i) elementary schools, and (I) secondary schools. 

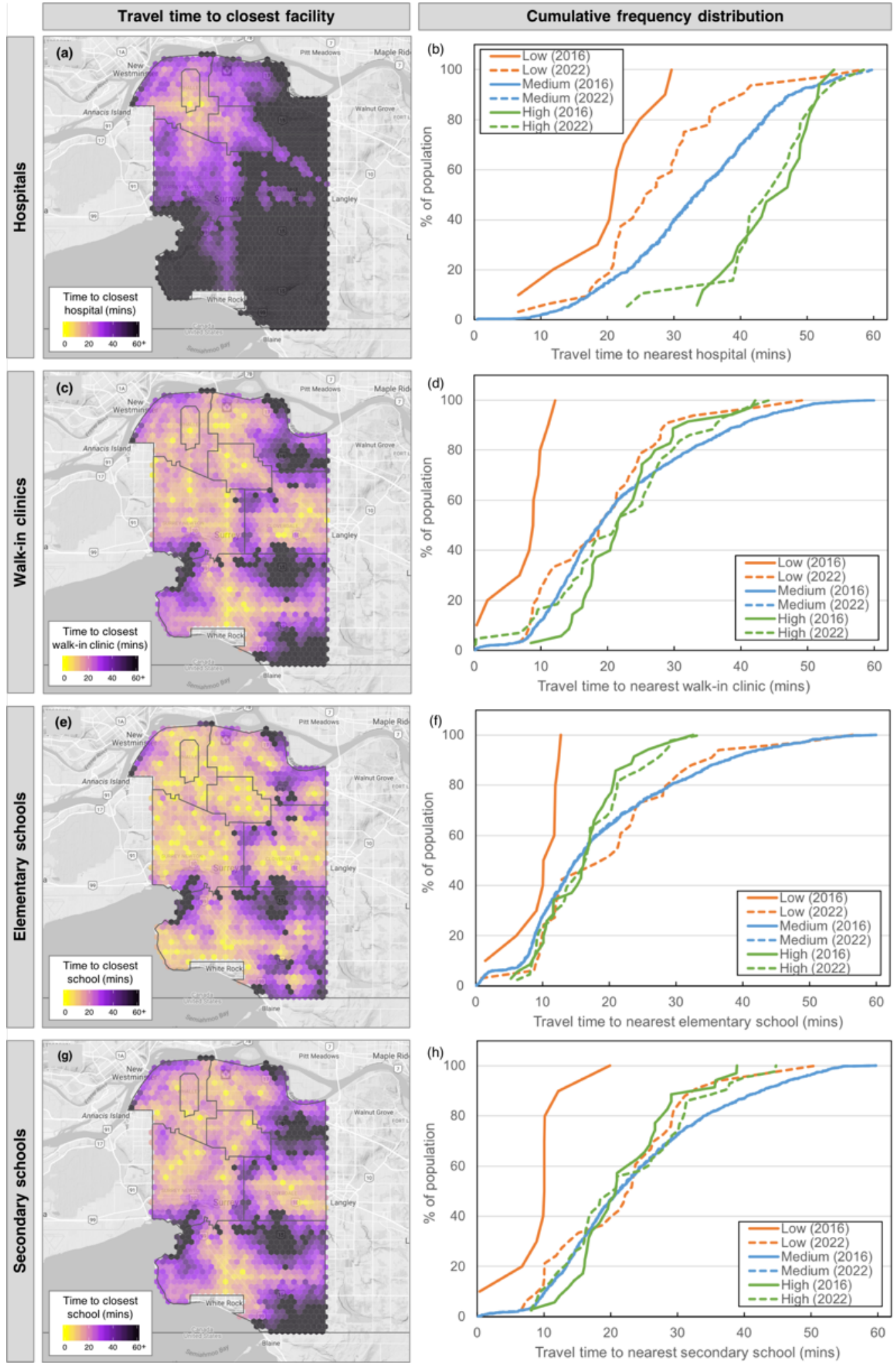

Figure 7 Spatial distribution of travel time to closest facility using public transport/walking for 2016, for a) hospitals, (c) walk-in clinics, (e) elementary schools, and (g) secondary schools. Cumulative frequency distributions of travel time to closest facility for each cell, grouped by the median household income for each cell (low, medium and high income) for both 2016 and 2022, for (b) hospitals, (d) walk-in clinics, (f) elementary schools, and (h) secondary schools. 


\subsubsection{Destination-oriented accessibility}

Destination-oriented, or 'passive', accessibility statistics are displayed in Figure 8. City-wide population growth results in a large increase in the catchments of hospitals $(\sim 9,000$ more people, all ages combined), walk-in clinics $(\sim 124,000$, all ages combined) and schools ( 11,000 more children/youth) (Figure 8a,b). This absolute increase in population with access to healthcare facilities masks a slight overall decrease in the mean proportion of all households within the catchments (as shown by the percentages on the bars). The number of low-income and high-income households in the catchments of healthcare facilities and schools will increase from 2016 to 2022, whilst the number of medium-income households will decrease (Figure $8 \mathrm{c}, \mathrm{d}$ ). This is partly attributable to the re-categorization of households at the bottom end of the medium-income band in 2016 to low-income status in 2022. The proportion of households from each income band falling within the catchments will remain broadly stable across our study period.
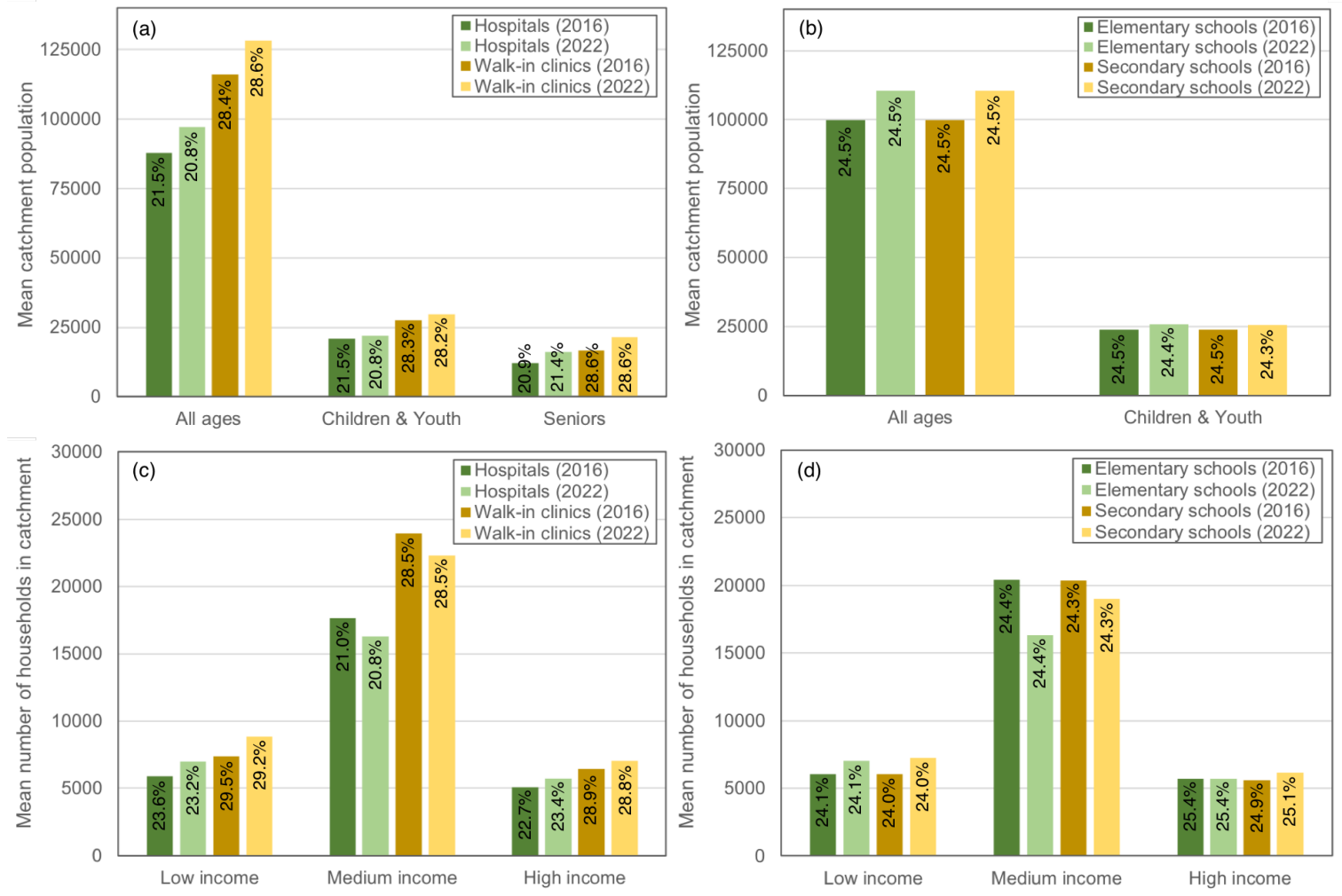

Figure 8 Destination-oriented ('passive') accessibility for a time travel threshold of 30 minutes by public transport/walking. Mean population residing within the catchments of each facility in 2016 and 2022, for (a) healthcare facilities, and (b) schools. Mean number of households located within the catchments of each facility in 2016 and 2022, divided by income group, for (c) healthcare facilities, and (d) schools. Percentages on each bar show the share of total population or household income category within the catchments. 


\subsubsection{Competition-based accessibility}

By combining our analysis of active and passive accessibility, we assessed a competitionbased accessibility metric for each facility type (Figure 9). In Figure 9a,c,e,g, darker colours represent higher potential user competition, and therefore lower accessibility levels; these plots complement the analyses presented above, highlighting relative spatial differences in competition. Areas with relatively low population growth and good hospital and clinic provision (e.g. Cloverdale) will be less affected by changes in accessibility demand than areas of rapid population growth and poor healthcare service provision (e.g. eastern South Surrey) (Figure $9 b, d)$. The rapid rate of senior population growth is already outpacing Surrey's provision of facilities: despite being home to $\sim 19 \%$ of Metro Vancouver's senior population, the city contains only $11 \%$ of its senior services (City of Surrey, 2012). Our results suggest increased accessibility demand amongst seniors could be a severe burden on healthcare facilities in the coming years. In the case of schools, the strongest pressure for places will be felt in the northern half of the city, and in southern and eastern parts of South Surrey, where population growth is relatively higher (Figure 9f,h).

Our hybrid competition-based accessibility metric presents a clearer picture of areas where access to services will be most affected by rapid population growth and poor service provision. The combination of larger catchment sizes for existing facilities and more people residing outside catchment areas likely requires a two-fold strategy. First, the city could provide incentives for better service provision, particularly in areas with high population growth where the business case is compelling. Second, the city and Translink should prioritize public transport investment in areas where competition-based accessibility is projected to decrease the most over the study period. A targeted approach to improving the accessibility of vulnerable groups will help make Surrey a more livable, workable and sustainable city. 

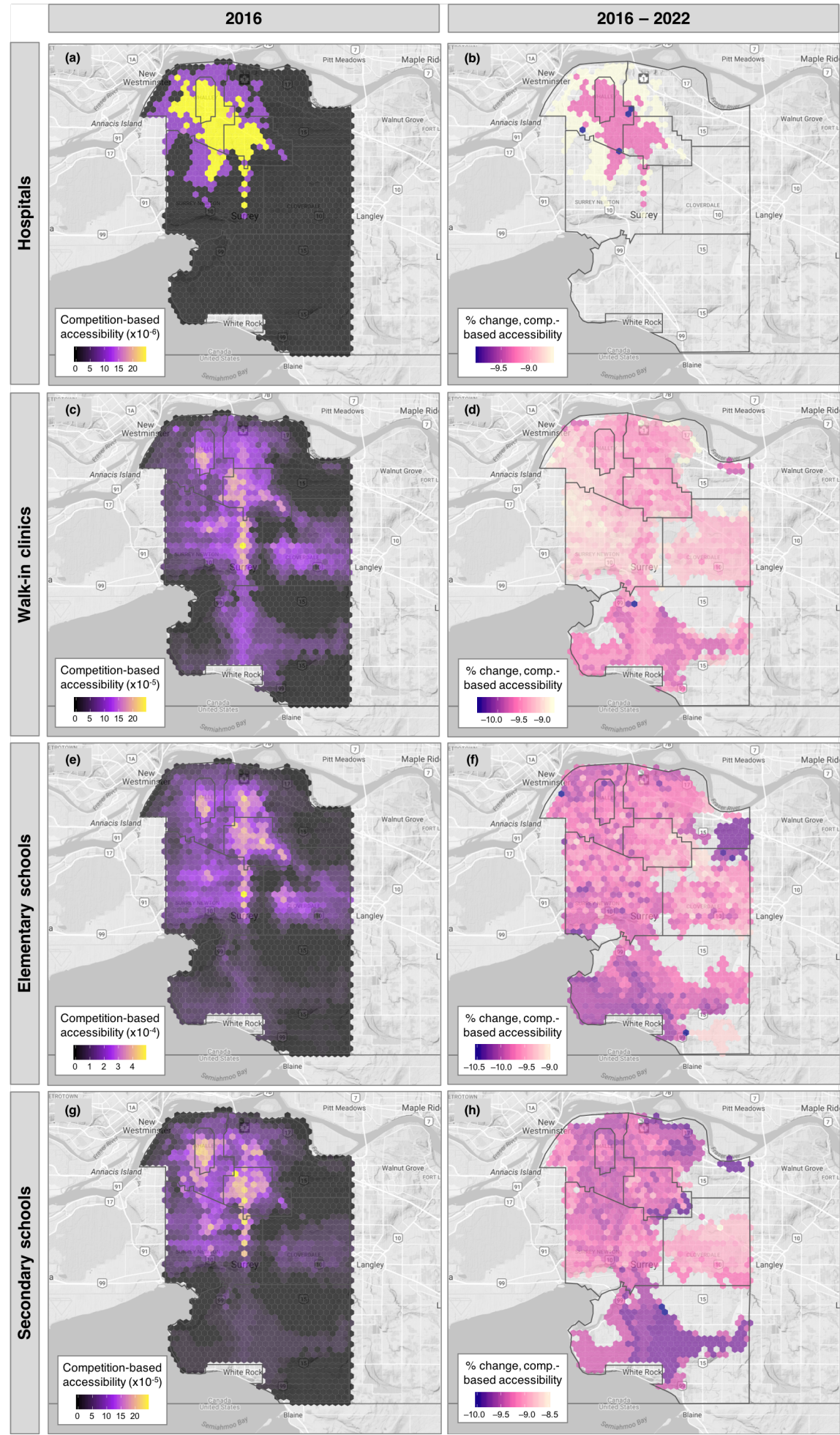

Figure 9 Competition-based accessibility, for a time travel threshold of 30 minutes by public transport/walking, for (a) hospitals, (c) walk-in clinics, (e) elementary schools, (g) secondary schools. Lower numbers (darker colours) represent the highest potential user competition for facilities, and therefore the lowest accessibility levels. Difference (from 2016 to 2022) in the competition-based metric for (b) hospitals, (d) walk-in clinics, (f) elementary schools, and (h) secondary schools. Lower numbers (bluer colours) represent a greater decline in accessibility due to increased competition for facilities. Total population (all ages combined) was used to assess competition for healthcare facilities, while only the children/youth population was used to assess competition for schools. 


\section{Conclusions}

Assessing shifts in accessibility demand across a city is vital for ensuring optimal distribution of investment in services and urban infrastructure. In this study, we examined the distribution of population growth by income and age in the City of Surrey, and what impact this might have on the catchment sizes of educational and healthcare facilities using realistic transportation routing. We payed close attention to two vulnerable sub-populations, children/youth and seniors, as these are often not the primary beneficiaries of high-capital investment.

Demographic changes between 2016 and 2022 will contribute to larger catchment sizes for many facilities, which may create service bottlenecks in some areas. At the same time, people are projected to move into areas with no current access to facilities, which raises questions about equity of access for vulnerable populations. Different age and income groups move differently around a city, such that certain travel modes are more relevant to certain demographic and socio-economic profiles. Like many North American cities, most of Surrey's residents rely heavily on private vehicles to get around, with only $20 \%$ using the public transportation system at least semi-regularly (City of Surrey, 2014). While our results show many medium-income households will experience a decline in theoretical accessibility over the study period, high car ownership and usage in this income band means the decline may be unproblematic in reality. However, low-income and senior-residents moving into areas with poor accessibility will likely be much more reliant on public transport, so accessibility equity may decline. Balancing the accessibility needs of vulnerable groups with broader transportation needs for economic growth will increasingly be a challenge for many modern cities like Surrey.

In this study we introduced a hybrid competition-based accessibility metric, which essentially combines active (origin-oriented) and passive (destination-oriented) accessibility measures. By taking account of how many facilities are reachable from any given origin, and how many other residents are competing for the same facilities, we indicated where services and infrastructure might face the most pressure in future. Our hybrid accessibility metric does not currently account for the capacity of facilities (i.e. the actual number of hospital beds and school places), because this information was not available in open-source formats. Including capacity data, as has been proposed by a variety of scholars (e.g. Wilson, 1971; Shen, 1998; van Wee et al., 2001), would increase the value of our metric for the purposes of planning and investment.

Whilst the scope of our study limited us to assuming an unchanged transport network and unaltered facilities provision between 2016 and 2022, we must acknowledge that cities do 
usually respond to population change by investing in infrastructure - albeit not always in the most optimal fashion. Building on our methodology, future studies could investigate the impact of planned transportation interventions (e.g. a Light Rail Transit in Surrey) by deriving synthetic datasets for roads, transit routes and timetabling, and evaluating 'ex-ante' accessibility impacts of different policy and investment scenarios (e.g. Pereira, 2018a). Integrating different scenarios with models of urban land use (e.g. Meiyappan et al., 2014) would allow for heterogeneous population downscaling, and also for more realistic spatial allocation of facilities. This would facilitate comparative analyses of the impacts of greenfield development versus urban densification and infill on accessibility equity (Quiros et al., 2015; Sola et al., 2018).

It will also be beneficial to account for diverse socio-behavioral decision-making in the context of accessibility, rather than assuming homogenous user preferences and fixed behaviors along transportation networks; indeed, the heterogeneity of urban populations precludes universally valid mobility solutions (Hager et al., 2015). For instance, agent-based models (ABMs), validated using the types of high-resolution census data presented in this study, can simulate transport users as agents with their own schedules and criteria for weighting travel time, cost, comfort and ecological impact (Zhang \& Levinson, 2005; Bazzan \& Klügl, 2014). Disaggregating travel behavior in this way will lead to more accurate forecasts of travel demand, and hence provide a more nuanced understanding of accessibility (Batty, 2013).

Our study demonstrates the valuable insights on accessibility that can be derived from the vast arrays of open public data and open-source code that are now available to researchers. Combined with evolving methodologies such as ABMs and land use modelling, these data will become increasingly valuable for informing the policies, planning and design of future smart cities that improve quality of life for citizens.

\section{Acknowledgements}

We thank the Pacific Institute for Climate Solutions (PICS) and Cascadia Urban Analytics Cooperative (CUAC) for partly funding this research. 


\section{References}

Apparicio, P., Abdelmajid, M., Riva, M. \& Shearmur, R. (2008). Comparing alternative approaches to measuring the geographical accessibility of urban health services: distance types and aggregation-error issues. International Journal of Health Geography, 7(7), 1-14.

Batty, M. (2013). Big data, smart cities and city planning. Dialogues in Human Geography, 3, 274-279.

Bazzan, A. \& Klügl, F. (2014). A review on agent-based technology for traffic and transportation. The Knowledge Engineering Review, 29(3), 375-403.

Bissonnette, L., Wilson, K., Bell, S. \& Shah, T. I. (2012). Neighbourhoods and potential access to health care: the role of spatial and aspatial factors. Health Place 18 (4), 841-853.

Boisjoly, G. \& El-Geneidy, A. M. (2017). How to get there? A critical assessment of accessibility objectives and indicators in metropolitan transportation plans. Transport Policy, 55, 38-50. doi:10.1016/j.tranpol.2016.12.011

City of Surrey (2012). Community Demographic Profiles. http://www.surrey.ca/businesseconomic-development/1417.aspx [accessed November 2017]

City of Surrey (2013). Official Community Plan. http://www.surrey.ca/city-services/1318.aspx [accessed January 2018]

City of Surrey (2014). Community Energy and Emissions Plan. http://www.surrey.ca/community/11119.aspx [accessed January 2018]

City of Surrey (2016). Sustainability Charter 2.0. http://www.surrey.ca/community/3568.aspx [accessed November 2017]

City of Surrey (2017). Financial Plan 2017-2021. http://www.surrey.ca/citygovernment/3077.aspx [accessed January 2018]

Dai, D. (2010). Black residential segregation, disparities in spatial access to health care facilities, and late-stage breast cancer diagnosis in metropolitan Detroit. Health Place, 16(5), 1038-1052.

Darcy, S. (2003). The politics of disability and access: the Sydney 2000 Games experience. Disability \& Society, 18(6), 737-757. doi:10.1080/0968759032000119497

de Jong, M., Joss, S., Schraven, D., Zhan, C. \& Weijnen, M. (2016) Sustainable-smartresilient-low carbon-eco-knowledge cities: Making sense of a multitude of concepts promoting sustainable urbanization. Journal of Cleaner Production, 109, 25-38.

Delmelle, E.C. \& Casas, I. (2012). Evaluating the spatial equity of bus rapid transit-based accessibility patterns in a developing country: The case of Cali, Colombia. Transport Policy, 20, 36-46. doi:10.1016/j.tranpol.2011.12.001

El-Geneidy, A. \& Levinson, D. (2011). Place rank: Valuing spatial interactions. Networks and Spatial Economics, 11(4), 643-659. 
El-Geneidy, A., Levinson, D., Diab, E., Boisjoly, G., Verbich, D. \& Loong, C. (2016). The cost of equity: Assessing transit accessibility and social disparity using total travel cost. Transportation Research Part A: Policy and Practice, 91, 302-316. doi:10.1016/j.tra.2016.07.003

Gage, A.J. \& Calixte, G. M. (2006). Effects of the physical accessibility of maternal health services on their use in rural Haiti. Population Studies, 60(3), 271-288.

Geurs, K. \& van Eck, J. (2003). Evaluation of accessibility impacts of land-use scenarios: the implications of job competition, land-use, and infrastructure developments for the Netherlands. Environment Planning B, Environmental Design, 30(1), 69-87.

Geurs, K. T. \& van Wee, B. (2004). Accessibility evaluation of land-use and transport strategies: Review and research directions. Journal of Transport Geography, 12(2), 127-140.

Goddard, M. \& Smith, P. (2001). Equity of access to health care services: Theory and evidence from the UK. Social Science in Medicine, 53, 1149-1162.

Guagliardo, M. F. (2004). Spatial accessibility of primary care: concepts, methods and challenges. International Journal of Health Geographics 2004, 3(3), 1-13.

Hager, K., Rauh, J. \& Rid, W. (2015). Agent-based modeling of traffic behavior in growing metropolitan areas. Transportation Research Procedia 10, 306-315.

Hansen, W. G. (1959). How accessibility shapes land use. Journal of the American Institute of Planners, 25, 73-76.

Hickford, A. J., Nicholls, R. J., Otto, A., Hall, J. W., Blainey, S. P., Tran, M. \& Barua, P. (2015). Creating an ensemble of future strategies for national infrastructure provision. Futures, 66, 13-24. doi:10.1016/j.futures.2014.11.009.

Hiscock, R., Pearce, J., Blakely, T. \& Witten, K. (2008). Is neighborhood access to health care provision associated with individual-level utilization and satisfaction? Health Services Research, 43(6), 2183-2200.

Human Early Learning Partnership (2016). EDI (Early Years Development Instrument) report. Wave 6 Community Profile: Surrey (SD36). University of British Columbia, School of Population and Public Health, Vancouver, Canada.

Kawakami, N., Winkleby, M., Skog, L., Szulkin, R. \& Sundquist, K. (2011). Differences in neighborhood accessibility to health-related resources: a nationwide comparison between deprived and affluent neighborhoods in Sweden. Health Place, 17 (1), 132-149.

Kwan, M. -P. (1998). Space-time and integral measures of individual accessibility: a comparative analysis using a point-based framework. Geographical Analysis, 30, 191-216.

Loo, B. P. Y., Wing, W. \& Lam, Y. (2012). Geographic accessibility around health care facilities for elderly residents in Hong Kong: a microscale walkability assessment. Environment Planning B: Planning Design, 39(4), 629-646. 
Lucas, K., van Wee, B. \& Maat, K. (2015). A method to evaluate equitable accessibility: combining ethical theories and accessibility-based approaches. Transportation, 1-18. doi:10.1007/s11116-015-9585-2

Lutz, W., Sanderson, W. \& Scherbov, S. (2008). The coming acceleration of global population ageing. Nature, 451, 716-719.

Meiyappan, P., Dalton, M., O'Neill, B. C. \& Jain, A. K. (2014). Spatial modeling of agricultural land use change at global scale. Ecological Modelling, 291, 152-174.

Milakis, D., Cervero, R., Van Wee, B. \& Maat, K. (2015). Do people consider an acceptable travel time? Evidence from Berkeley, CA. Journal of Transport Geography, 44, 76-86.

Mokhtarian, P. L. \& Salomon, I. (2001). How derived is the demand for travel? Some conceptual and measurement considerations. Transportation research part A: Policy and Practice, 35(8), 695-719.

Neutens, T. (2015). Accessibility, equity and health care: review and research directions for transport geographers. Journal of Transport Geography, 43, 14-27. doi:10.1016/j.jtrangeo.2014.12.006

Neutens, T., Schwanen, T., Witlox, F. \& De Maeyer, P. (2010). Equity of urban service delivery: A comparison of different accessibility measures. Environment and Planning A, 42(7), 1613-1635.

Open Trip Planner (2017). https://github.com/opentripplanner/OpenTripPlanner [accessed November 2017]

Otto, A., Hall, J. W., Hickford, A. J., Nicholls, R. J., Alderson, D., Barr, S. \& Tran, M. (2016). A quantified system-of-systems modeling framework for robust national infrastructure planning. IEEE Systems Journal, 10(2), 385-396.

Papa, E. \& Coppola, P. (2012). Gravity-based accessibility measures for integrated land-use planning (GraBAM). In: Hull, A., Silva, C. \& Bertolini, L. (eds). Accessibility Instruments for Planning Practice. COST Office, 117-124.

Pereira, R. (2017). OTP Travel Time Matrix. https://github.com/rafapereirabr/otp-travel-timematrix [accessed November 2017]

Pereira, R. H. M. (2018a). Ex-ante evaluation of the accessibility impacts of transport policy scenarios: equity and sensitivity to travel time thresholds for Bus Rapid Transit expansion in Rio de Janeiro. Journal of Transport Geography. doi:10.17605/OSF.IO/SUT7R

Pereira, R. H. M. (2018b). Transport legacy of mega-events and the redistribution of accessibility to urban destinations. Cities. 10.1016/j.cities.2018.03.013

Pereira, R. H. M., Schwanen, T. \& Banister, D. (2017). Distributive justice and equity in transportation. Transport Reviews, 37(2), 170-191. doi:10.1080/01441647.2016.1257660

Quiros, T. P. \& Mehndiratta, S. R. (2015). Accessibility analysis of growth patterns in Buenos Aires, Argentina: Density, employment, and spatial form. Transportation Research Board, 2512. doi:10.3141/2512-12 
Ryan, J., Wretstrand, A. \& Schmidt, S. M. (2015). Exploring public transport as an element of older persons' mobility: A Capability Approach perspective. Journal of Transport Geography, 48, 105-114.

Shen, Q. (1998). Location characteristics of inner-city neighborhoods and employment accessibility of low-wage workers. Environment Planning B, Planning Design, 25(3), 345-365.

Shirocca Consulting (2015). Economic benefits of Surrey LRT. http://www.surrey.ca/files/Economic_Benefits_of_Surrey_LRT.pdf [accessed January 2018]

SimplyAnalytics (2017a). Census 2016 Current Estimates Data; Census 2022 Projected Estimates. [data retrieved January, 2018, from DemoStats database]

SimplyAnalytics (2017b). Data Providers, Definitions and Methodology Information: https://simplyanalytics.zendesk.com/hc/en-us/articles/115003011663-Data-ProvidersDefinitions-and-Methodology-Information [accessed January 2018]

Sola, A. G., Vilhelmson, B. \& Larson, A. (2018). Understanding sustainable accessibility in urban planning: Themes of consensus, themes of tension. Journal of Transport Geography, 70, 1-10. doi: 10.1016/j.jtrangeo.2018.05.010

Statistics Canada (2017). http://www12.statcan.gc.ca/ [accessed January 2018]

Thrift, N. (2014). The promise of urban informatics: Some speculations. Environment Planning A, 46, 1263-1266.

Translink (2018). https://m.translink.ca/Fares-and-Passes/ [accessed January 2018]

United Nations (2015). Transforming our World: The 2030 Agenda for Sustainable Development.

United Nations Commission on Science and Technology for Development (2015). Smart Cities and Infrastructure. UNCTD, Budapest, Hungary

Vandenbulcke, G., Steenberghen, T. \& Thomas, I. (2009). Mapping accessibility in Belgium: a tool for land-use and transport planning? Journal of Transport Geography, 17, 39-53.

van Wee, B., \& Geurs, K. (2011). Discussing equity and social exclusion in accessibility evaluations. European Journal of Transport and Infrastructure Research, 11(4).

van Wee, B., Hagoort, M. \& Annema, J. A. (2001). Accessibility measures with competition. Journal of Transport Geography, 9(3), 199-208.

Wachs, M. \& Kumagai, T. (1973). Physical accessibility as a social indicator. Socioeconomic Planning Science, 7, 327-456.

Weibull, J. W. (1976). An axiomic approach to the measurement of accessibility. Regional Science and Urban Economics, 6, 357-379.

Weiss, D.J. et al. (2018). A global map of travel time to cities to assess inequalities in accessibility in 2015. Nature. doi:10.1038/nature25181 
Wessel, N., Allen, J. \& Farber, S. (2017). Constructing a routable retrospective transit timetable from a real-time vehicle location feed and GTFS. Journal of Transport Geography, 62, 92-97. doi:10.1016/j.jtrangeo.2017.04.012

Wilson, A. (1971). A family of spatial interaction models, and associated developments. Environment Planning, 3(1),1-32.

Zhang, L. \& Levinson, D. (2005). Agent-based approach to travel demand modeling: Exploratory analysis." Transportation Research Record, 1898, 28-36. doi: 10.3141/1898-04 